\title{
Religiosidad femenina y herejía: monjas y beatas «luteranas» ante la Inquisición de Sevilla en tiempos del Emperador
}

\section{Religiosity and female heresy nuns and «Lutheran» lay sisters before the Inquisition of Seville in the time of Emperor}

Michel Boeglin

michel.boeglin@univ-montp3.fr

Université Montpellier 3 - IRIEC

Resumen: Durante la represión del luteranismo en Sevilla (1557-1565), las mujeres representaron un porcentaje importante de los condenados. $Y$ entre las supliciadas destacan mujeres que desempeñaron un papel y un rol central en la difusión de las nuevas doctrinas. Nos centraremos más particularmente en el caso de las religiosas y beatas procesadas en aquella ocasión.

Palabras clave: Sevilla, Siglo XVI, Luteranismo, Inquisición, mujeres

\begin{abstract}
During the repression of Lutherian heresy in Seville (1557-1565), women represented a significant percentage of the convicted. And among the persons sentenced to death, women played a central role in the spread of the new doctrines. We will focus more particularly on the case of religious and «beatas» judged on that occasion.
\end{abstract}

Keywords: Seville, XVIth century, Lutheranisme, Inquisition, women 
Michel Boeglin. Religiosidad femenina y herejía: monjas y beatas «luteranas» ante la Inquisición de Sevilla en tiempos del Emperador

Si el caso de las beatas y religiosas procesadas por la Inquisición por alumbradismo es objeto de un renovado interés estos últimos años (Weber 2016), en cambio el estudio de las religiosas procesadas, y de forma más general, de las mujeres procesadas por luteranismo a finales de la década de 1550 ha sido aún poco profundizado, tanto en Valladolid como en Sevilla. ${ }^{1}$ La desaparición de gran parte de los procesos, la dispersión de fuentes relativas a estas así como el relativo desinterés durante largo tiempo por aquellas creyentes y su historia explican en parte el silencio a su respecto y nos centraremos aquí sobre el caso sevillano en las causas de luteranismo.

En el otoño de 1557, cuando los inquisidores tuvieron noticia de un tráfico de libros de propaganda protestante en Sevilla, rápidamente descubrieron que no se encontraban ante una simple tentativa de introducir obras reformadas en la capital de la Bética. Se confirmaba que se enfrentaban a la difusión, en distintos círculos de la sociedad hispalense, de doctrinas contrarias a la ortodoxia tal y como acababa de redefinirse durante las primeras sesiones del Concilio de Trento, muy especialmente en la de 1547 sobre la justificación.

La religiosidad de algunas figuras destacadas de la denominada «comunidad» de Sevilla -aunque más bien debiera hablarse de los círculos de Sevilla, dada la variedad de grupos procesadosno se limita a una simple reformulación de tesis erasmistas como se ha afirmado a menudo a continuación de Marcel Bataillon (1991, I: 568-570: 750-753), sino que revela una convergencia hacia diversos puntos doctrinales de la Reforma y, a veces, una adhesión al núcleo de la doctrina protestante.

Es evidente a la lectura de las sentencias conservadas del conjunto de los acusados castellanos de luteranismo que no todos los acusados se enrolaban en un mismo movimiento de disidencia. Pero entre ellos, destacan determinadas figuras femeninas, en particular en el núcleo de clara advocación protestante y estas se caracterizaban por su protagonismo activo en distintos diferentes círculos heterodoxos de la capital sevillana. Algunas religiosas además se vieron juzgadas y condenadas y entre ellas destaca la monja Francisca de Chaves, cuya trayectoria revela el papel central que podían aun desempeñar a mediados del XVI las mujeres dentro de aquellos colectivos clandestinos que abogaban por una profunda reforma de la vida y las experiencias religiosas.

\section{1557-1562: el desarraigo del luteranismo en Sevilla}

Más que una sola comunidad, lo que revela tanto la cronología de las detenciones que se extienden a lo largo de cuatro años, de 1557 a 1560, como la parcelaria documentación respecto a la represión del luteranismo en Sevilla es la existencia de diversos círculos de distinta obediencia religiosa pero que se reunían en un punto: una marcada sensibilidad para con el difuso sentimiento de la justificación por la fe. Empecemos por los datos de esta represión a través de las condenas, que se

1 Con la excepción de Tellechea Idígoras (2004) para la capital vallisoletana. 
Michel Boeglin. Religiosidad femenina y herejía: monjas y beatas «luteranas» ante la Inquisición de Sevilla en tiempos del Emperador

extienden en su gran mayoría entre 1559 y 1562 aunque prosiguió la represión hasta 1565, como lo enseña el siguiente cuadro.

Inquisición de Sevilla (1559-1565): Sentencias pronunciadas contra protestantes procedentes de la Península ibérica

\begin{tabular}{|c|c|c|c|c|c|c|c|c|c|c|c|c|c|c|c|}
\hline \multirow[b]{2}{*}{ Sexo } & \multicolumn{2}{|c|}{1559} & \multicolumn{2}{|c|}{$\overline{1560}$} & \multicolumn{2}{|c|}{1562} & \multicolumn{2}{|c|}{1563} & \multicolumn{2}{|c|}{1564} & \multicolumn{2}{|c|}{1565} & \multicolumn{3}{|c|}{$1559-1565$} \\
\hline & $H$ & $M$ & $H$ & $M$ & $H$ & $M$ & $H$ & $M$ & $H$ & $M$ & $H$ & $M$ & Total & & $\begin{array}{l}\text { n y } \% \text { de } \\
\text { eres }\end{array}$ \\
\hline $\begin{array}{l}\text { Relajación en } \\
\text { persona }\end{array}$ & 10 & 5 & 2 & 9 & 12 & & & & & & & & 38 & 14 & $36,8 \%$ \\
\hline $\begin{array}{l}\text { Relajación en } \\
\text { estatua }\end{array}$ & 1 & & 3 & & 15 & & & & & 1 & 2 & & 22 & 1 & $4,5 \%$ \\
\hline Reconciliación & 5 & 1 & 3 & 9 & 6 & 3 & & & 1 & & & & 28 & 13 & $46,4 \%$ \\
\hline $\begin{array}{l}\text { Abjuración de } \\
\text { vehementi }\end{array}$ & & & 3 & 1 & 11 & 6 & 4 & 1 & & & 2 & & 28 & 8 & $28,6 \%$ \\
\hline Abjuración de levi & & & 4 & 1 & & 2 & 1 & & & & & & 8 & 3 & $37,5 \%$ \\
\hline «Penitenciado» & 2 & & & & 1 & 2 & & & & & & & 5 & 2 & $40,0 \%$ \\
\hline Total & 18 & 6 & 15 & 20 & 45 & 13 & 5 & 1 & 1 & 1 & 4 & 0 & 129 & 41 & $31,8 \%$ \\
\hline
\end{tabular}

De las 212 causas de protestantismo juzgadas entre 1559 y 1565 , el 61,3 \% fueron incoadas a españoles o portugueses. Salvo contados casos de genoveses y flamencos, no se tiene constancia de relaciones entre las comunidades de extranjeros asentados en Sevilla y los condenados de la Bética.

Cojamos por tanto los procesos de peninsulares únicamente. La represión alcanzó niveles de descomunal violencia en estos seis años. De estos 129 reos peninsulares, 38 (el 29,4 \%) acabaron en la hoguera, señal de una reacción inusual de la maquinaria inquisitorial de mediados del siglo Xvi; el $21 \%$ de los reos fueron reconciliados y la misma proporción abjuró de vehementi cuando los jueces no habían logrado demostrar su culpabilidad. Además, veintidós efigies de acusados huidizos o fallecidos fueron quemadas, muchas de ellas de monjes del convento de San Isidoro del Campo, cenobio de ermitaños de San Jerónimo, cuyos miembros habían huido a Ginebra poco antes de la redada hecha por el Santo Oficio.

En cambio, se registran poquísimas abjuraciones de levi, lo cual señala que la Inquisición quiso dar un golpe fortísimo y marcar las conciencias señalando las fronteras religiosas poco antes de finalizar el concilio de Trento y marcar las diferencias con actitudes religiosas poco antes aún toleradas.

Entre los condenados, las mujeres fueron particularmente presentes, señal de una receptividad muy fuerte a las doctrinas de los novadores y de un papel central en la difusión de dichas doctrinas. 
Michel Boeglin. Religiosidad femenina y herejía: monjas y beatas «luteranas» ante la Inquisición de Sevilla en tiempos del Emperador

Es más: constituyen una parte significativa de los reos sentenciados con penas condenatorias. Entre los reos de la Península (España y Portugal), las mujeres representan el 31,8\% de los acusados, un porcentaje muy elevado, muy por encima del porcentaje habitualmente registrado entre los condenados en causas de cristianos viejos (entre un 5 y un 10\% en general). Y entre los relajados en persona, las mujeres representan casi la mitad de los ejecutados (46,4\%). Es más, dado el elevado número de eclesiásticos procesados ( $46 \%$ de los reos), si tomamos como base de referencia únicamente a los legos, las procesadas representan el 50\% del total (Boeglin 2006: 363). En una época en que las mujeres disponen de un margen de actuación reducido, su papel en la recepción y en la difusión de las nuevas doctrinas o «novedades» resulta llamativo, como es el caso también para la otra herejía contemporánea del luteranismo, el alumbradismo.

\section{Mujeres seglares, beatas y religiosas «luteranas»}

Ciertos monasterios femeninos habían sido el centro de la predicación del doctor Juan Gil, alias Egidio. Este antiguo profesor de Alcalá de Henares había llegado a principios de la década de 1530 a Sevilla llamado por el arzobispo Manrique y fue rápidamente elevado a la canonjía magistral de Sevilla. Su papel en la predicación centrada en la justificación por la fe así como en la organización de los círculos clandestinos es patente. El convento de Santa Paula en Sevilla había sido uno de ellos. Una de las hermanas jerónimas, Ana de los Ángeles, en una carta de confesión mandada a los inquisidores señalaba la relación estrecha de éste con «la s[eñor]a priora que entonzes era»: con motivo de las prédicas de Egidio puntualizaba la religiosa,

todo el convento e todo el recibimi[ent]o de afuera estava lleno de gente [y] preguntada qué gente de fuera avía en el dicho recibimi[ent]o dixo que mucha gente que le siguía e que oýa dezir que estava allí aquella Bohorques e Birués q[ue] quemaron y otras muchas personas, hombres y mujeres que le siguían. ${ }^{2}$

La «beata» María de Bohórques, de 26 años, y María de Virués, mujeres a las que se refiere la jerónima, figuraron entre las primeras supliciadas. María de Bohorques era la hija natural de Pedro García de Jerez y Bohorques jurado e importante caballero de Sevilla. Era calificada de «beata» en la correspondencia del tribunal: aquello, en la realidad religiosa andaluza del XVI podía remitir tanto a una terciaria de alguna orden, como una mujer que se ponía bajo la dirección espiritual de un confesor u otra persona. Pero también podía remitir a una mujer que vestía el hábito de su propia iniciativa sin estar bajo la dirección de ningún director de conciencia específico y parece haber sido aquí el caso. ${ }^{3}$ Apenas tenía 26 años cuando fue juzgada y dominaba a la perfección el latín y el griego y conocía de memoria amplios fragmentos de las Sagradas Escrituras. Una relación

2 AHN (Archivo Histórico Nacional) Inq, leg. 2942 exp. 88. La mayoría de los documentos citados en el presente artículo pueden consultarse en López Muñoz 2011: II.

3 AHN Inq. leg. 2946 exp. s/n, carta del 17/12/1575. Publicada en Huerga 1988: IV, 99-101.

SCRIPTA, Revista internacional de literatura i cultura medieval i moderna, núm. 8 / desembre 2016 / pp. 164-178 ISSN: 2340-4841 · doi:10.7203/SCRIPTA.8.9293 
Michel Boeglin. Religiosidad femenina y herejía: monjas y beatas «luteranas» ante la Inquisición de Sevilla en tiempos del Emperador

anónima del auto de fe de 1559 indica que las interpretaba en conformidad con los comentarios de Lutero sobre las obras, la justificación por la fe, los méritos de Cristo, los sacramentos y los rasgos distintivos de la verdadera iglesia (BNE (Biblioteca Nacional Española) ms 6176 fo 302r-v). Poseía y conocía de memoria diversos libros luteranos, sin que se detalle los títulos o autores que conocía.

Pudo haber sido «dogmatizada» por Gaspar Baptista, discípulo y criado del canónigo Egidio, como lo fue una de sus amigas (AHN Inq. leg. 4514 exp. 15), y también habían tenido importante efecto en ella, parece, las prédicas de Casiodoro de Reina hechas en el círculo de don Juan Ponce de León (BNE ms 6176 f 302 v). Según se destaca de la correspondencia administrativa, también entraba en el convento de Santa Paula y platicaba duraderamente con las monjas acompañada por otras personas, probablemente su amiga María de Virués y otras deudas. ${ }^{4}$ Posiblemente, como discípulas de Egidio leídas y convencidas por las doctrinas reformadas, prosiguieran la labor de adoctrinamiento de las religiosas más abiertas a las nuevas doctrinas. Hasta al tablado se negó a abandonar su profesión de fe y desesperó a los frailes encomendados para sacarle su confesión ante su conocimiento de la doctrina y sus convicciones: según una relación anónima del auto de fe, la moza

sabía muy bien latín y parte de la lengua griega. Y esta sabiduría fue parte de su locura y ceguedad, dando a entender que todos eran necios, y aun hasta los inquisidores, diciendo q ella entendía también la lengua como ellos, y que entendía sobre el sentido literal como escritural de la Sagrada Escritura, y que lo que ella dijese acerca desto era ansí y que lo demás no lo había de creer.

Era tanta la suma e copia de Escritura que sabía, que admiraba a los frailes, y toda ella traída a sentido luterano, aunque las dichas autoridades en la letra sonaba otra cosa a que ella las moralizaba, diciendo también que ella tenía libros que declaraban la dicha Escritura en aquel sentido (BNE mss 6176 fo $312 \mathrm{v}$ ).

María Bohorques y su amiga María de Virués habían sido relajadas junto con dos otras mujeres, aparentemente jóvenes también y solteras («mujeres honestas» indica la relación de causas), amigas suyas según se relata en el martirologio de las víctimas evangélicas de Sevilla, el Reginaldo González. Montes: María Cornejo e Isabel de Baena (Reginaldo 1991: 381). En sus casas se habían celebrado conventículos y ceremonias reformadas y estas damas habían tenido un protagonismo particularmente activo. La vivienda de Baena fue arrasada y sembrada de sal, señal de la gravedad de las celebraciones heréticas que se habían realizado allí. ${ }^{5}$

4 AHN Inq. leg. 2942 exp. 88: carta del 2.9.1560. « se ayuntaban señoras y otras personas a oír aquellos sermones y entraban dentro en el convento [de Santa Paula] a tratar y comunicar con las religiosas María de Bohorques y otras que fueron relajadas en el auto pasado...».

5 Ningún documento inquisitorial o relación de la época confirma la relación existente entre ellas. La relación anónima del auto de fe de 1559 de la BNE (ms 6176 f 299-304) solo evoca el caso de María de Bohorques y su hermana Juana, absuelta después de muerta en las cárceles inquisitoriales, y no menciona la relación que podía mantener con las tres otras mujeres, pero es verosímil. Todas pertenecían a una clase acomodada. 
Michel Boeglin. Religiosidad femenina y herejía: monjas y beatas «luteranas» ante la Inquisición de Sevilla en tiempos del Emperador

Aquellas cuatro muchachas fueron detenidas con otras mujeres de «las cercanías» de Sevilla si nos fiamos del testimonio en el martirologio de los evangélicos de Sevilla (Reginaldo 1991: 382): probablemente se trataba de la madre y las hijas Gómez, vecinas de Gibraleón, emparentadas con Catalina de Villalobos, quien estaba vinculada con las hermanas Manuel. Estas dos doncellas, hijas de un importante caballero de Sevilla, eran también discípulas de Egidio y adoctrinadas por el mismo Gaspar Baptista (Spach 1995: 867) y algunos miembros de su casa, como su criada Gerónima de Ayala con su marido Luis de Sosa, habían huido a Ginebra y se carteaban con ellas.

De las cartas de confesión entregadas por las religiosas de las jerónimas destaca el efecto profundo de las predicas de Egidio en el convento de santa Paula (AHN Inq. leg. 2942 exp. 78). Ceremonias y disciplinas «resfriadas», abandono de las devociones a santos, de las estaciones, de la oración vocal, etc. caracterizaban según varias monjas la atmósfera en el monasterio después de las prédicas del canónigo magistral centradas en los méritos de Cristo como clave de la salvación casi exclusivamente y que defendían un sentir más íntimo y más libre de la religión (López Muñoz 2011: I, 189-200).

Ahora bien, la incidencia en la herejía por parte de religiosas fue mucho probablemente más importante de que lo reflejan las cifras de las relaciones de causas, puesto que disponemos de contadas relaciones «fuera del auto» para aquellos años, es decir aquellas relaciones que recogían los casos de los reos cuyas causas no eran despachadas durante el auto de fe público sino de forma privada. En efecto, como había sido el caso en Valladolid donde determinados monasterios femeninos habían sido el centro de la predicación de los novadores, en particular de Agustín de Cazalla (Moreno Martínez 2013), el doctor Egidio y sus discípulos predicaron en diversos cenobios. El convento sevillano de Santa Paula fue el lugar donde predicó a menudo sermones centrados en los méritos de Cristo y la justificación por la fe, a finales de la década 1530 e inicios de la siguiente. ${ }^{6}$ Aquel monasterio fundado por doña Ana de Santillán en 1473, bajo la advocación de la santa discípula de San Jerónimo, estaba consagrado a la alabanza divina y al estudio de la Sagrada Escritura.

Ninguna monja parece haber sido encausada en este cenobio que fue objeto de numerosas visitas de Egidio, salvo una, la monja profesa Leonor de San Cristóbal, natural de la Isla de Madeira, en Portugal, quien abjuró de vehementi y cuya sentencia fue leída en el monasterio (AHN Inq, leg. 2075 exp. 2). Si no figura el detalle de sus delitos entre los elementos de la correspondencia del tribunal, su carta de confesión incorporada al proceso del doctor Egidio abierto poco años después de su fallecimiento, en 1559, da cuenta de la adhesión a la doctrina impregnada de enseñanzas de Juan de Valdés y pero también de los reformadores alemanes que difundía a través de las prédicas el canónigo mágistral (Pastore 2010: 291-302; Boeglin 2016: 212-221). Relataba en efecto en su carta de confesión:

Yo, Leonor de San Cristóbal, digo que habrá veinte y tantos años que, oyendo muchos sermones al doctor Egidio, le oí deshacer mucho las imágenes y nombrarlas por nombre de ídolos, e que idolatrábamos sin sentir reverenciándolas, que no habíamos de parar sino en lo del cielo.

6 Véase el testimonio de Leonor de San Cristóbal, más abajo. 
Michel Boeglin. Religiosidad femenina y herejía: monjas y beatas «luteranas» ante la Inquisición de Sevilla en tiempos del Emperador

Y más, que los santos que no nos podían ayudar en ninguna cosa, y que nuestras obras no eran nada, ni nuestras oraciones ni nuestro cantar. E que las órdenes y ceremonias, que todo eran cosas inventadas de hombres, y que no nos valían ninguna cosa. Y la causa era porque Jesucristo Nuestro Señor había obrado por todos nosotros. Y siempre parecía que favorecía a nuestra sensualidad, porque todas las cosas decía que hiciésemos conforme a como la voluntad nos diese, porque con aquello estaba Jesucristo más sosegado, porque esto era lo que más habíamos de procurar. De manera que si en la oración la voluntad nos diese estar asentadas, que así lo estuviésemos.

Deshacía las ceremonias, hábitos de religiosos que eran locura, cosas inventadas de hombres, y luego ponía una cobertura: «si San Jerónimo y Santo Domingo y los demás viniesen agora al mundo, que dirían: No es esta la orden que yo bice». Oyendo esto entendíamos que lo decía porque no éramos tan buenos como habíamos de ser, y así aplicábamos las cosas a buen fin, entendiendo que nos avisaba que no parásemos en nuestras cosas visibles.

Y acúsome si en ello ofendí a Nuestro Señor, que algunas veces oyendo tantas novedades deseé que fuesen vivas las madres pasadas, que trabajaron mucho por sustentar estas cosas de la orden, para que entendieran cómo no les aprovechaba ninguna cosa. Y otros resfriamientos y devociones de andar las estaciones y poner candelas a los santos, todo esto daba él por superfluo. Y así lo entendía yo hasta que lo prendieron la primera vez. Desde allí nunca más pensé en sus palabras y las aborrecí, así como cosa detestable y herética lo tengo (AHN Inq. leg. 2942, exp. 78).

Poco tiempo después, el 3 de agosto de 1560, el inquisidor Gasco mandó parecer ante ella la religiosa en el locutorio para pedirle ciertas aclaraciones en su confesión

Preguntada qué es lo que oyó decir y tratar a las monjas o a otras personas de lo que sentían o entendían del dicho doctor Egidio e de las cosas que decían al tiempo que las predicaba, e después aún, dijo que, al tiempo que las predicaba, como se las veían predicar en público y era tenido por un doctor tan excelentísimo, que todo el mundo le seguía. Que todas las cosas que predicaba le parescía una ley tan suave, una vida tan graciosa, que le parescía a esta declarante que lo demás de darse a trabajos y afligirse era cosa demasiada. E alguna vez, hablando con algunas monjas compañeras, decía «Quién pudiera tener agora vivas a nuestras antepasadas que tanto trabajaron en hacer y guardar estas obras y cerimonias de la orden, que tan poco les aprovecharon para su salvación, para que oyeran estos sermones e gozaran desta doctrina tan sin pesadumbre y no se fatigaran tanto por ellas, como es no trabajar tanto en el coro ni en rezar ni en otras cosas de Orden, pues que no les hacían al caso para su salvación».

Ítem, dijo que lo que le parece a esta declarante que se resfrió y sintió que había resfriamiento en las demás monjas fue en que en el claustro tienen tres imágenes de Nuestra Señora de diversas advocaciones, e solían los sábados andar por ellas en estación, cada una particularmente, diciendo la Salve en cada una de ellas. E después de haber oído al doctor Egidio lo susodicho, esta declarante se resfrió algo en parecer que, pues no hacía tanto al caso, bastaba decir la Salve y no andarlas todas. Y le parece que, aunque no se dejaban en la casa de andar aquellas estaciones, que no era con tanto fervor como de antes. Y que también se resfriaron en poner candelas a San Cosme y a San Damián y a San Marcos, y a otros santos particulares.

A continuación, su testificación fue recogida en el verano de 1560 en el convento por el inquisidor Gasco y fue detenida posteriormente: en diciembre del mismo año figuraba entre los prisioneros de la Inquisición. Solo se pueden hacer hipótesis al respecto de su encausamiento: el hecho de 
Michel Boeglin. Religiosidad femenina y herejía: monjas y beatas «luteranas» ante la Inquisición de Sevilla en tiempos del Emperador

ser una persona extranjera a la ciudad, que no procedía de los círculos del patriciado urbano de donde procedían muchas de aquellas religiosas podría explicar que en ella recayeran delaciones; o bien, habiendo sido maestra de novicias, su delito fue público en el convento y recayeron en ella las fuertes suspicacias de los jueces. En todos casos, fue leída su sentencia después del auto de fe del 28 de octubre de 1562 delante de todo el convento reunido, estando ella arrodillada y abjuró de vehementi y fue privada de oficio de maestra de novicias y portera y de cualquier otro oficio en el monasterio y se pedia que «siguiese continuamente el coro; y que no saliese del dicho monasterio» (AHN Inq. leg. 2075 exp. 2).

Igualmente otro convento femenino había sido afectado por las prédicas del doctor Egidio, según un correo del inquisidor Juan González de Munébrega, una casa de dominicas aunque el nombre no se menciona; pero las monjas se prevalecieron de un breve papal para no ser investigadas. ${ }^{7}$ Pero también fueron afectadas otras cosas, aunque no necesariamente por las prédicas del canónigo magistral. Así, entre las religiosas condenadas durante la represión anti-luterana figuraba una cierta Catalina de San Esteban, monja, natural de Écija y vecina de Sevilla. Según consta en la relación de causas era «hija de la comendadora de la Casa de la doctrina de las niñas», entender Casa de las niñas de la doctrina. No ha de confundirse con la Casa de los niños de la Doctrina que había sido un foco en que los heterodoxos sevillanos y número de discípulos de Egidio habían enseñado sino que se trata del nombre común dado al convento del Espíritu Santo de Sevilla, casa que en conformidad con sus estatutos recogía a las niñas pobres y huérfanas para darles sustento y educación (Montoto 2005: 135-136). ${ }^{8}$

Los datos relativos a sus delitos son inexistentes, pero llama la atención el hecho de que una religiosa saliera a abjurar un auto de fe público y que su retractación no tuviese lugar dentro del convento como solía ser la regla para las monjas; probablemente haya sido notorio o público el delito, lo cual explicaría la modalidad empleada a la hora de despacharse la sentencia. Puede haber sido acusada de enseñar doctrinas heterodoxas pues pedían los inquisidores «que perpetuamente no esté en casa de doctrina ni donde ejercite cosa de doctrina ni ella la pueda ejercitar enseñándola, sino siendo enseñada» (AHN Inq. leg. 2075 exp. 2). Catalina de Sant Esteban fue encerrada en un monasterio de su orden en la ciudad de Jerez, fuera de su lugar de residencia, «porque -especificaron los jueces- es de más observancia que otro alguno de su orden» (Ibid. leg. 2943, doc. 83).

7 AHN Inq. leg. 2942 exp. 88: carta del 2.9.1560. Ya puede tratarse del convento Santa María la Real, Santa María de Gracia o más probablemente del monasterio de la madre de Dios. Sobre estos cenobios, Morgado 1587: 150r sq.

8 De ser cierta la información de la relación de causas, sería hija de la iniciadora del centro de acogida a muchachas pobres y comendadora doña Inés Méndez de Sotomayor, pues en 1560 según Montoto, seguía siendo a la cabeza de la comunidad y compraba un nuevo solar para trasladar las hermanas y niñas recogidas, a no ser que se tratara de una de las hijas de la fundadora del convento y comendadora perpetua, doña Maria de Aguilar, natural de Málaga. 
Michel Boeglin. Religiosidad femenina y herejía: monjas y beatas «luteranas» ante la Inquisición de Sevilla en tiempos del Emperador

\section{Francisca de Chaves «apóstata luterana, dogmatizadora y enseñadora de la dicha secta»}

Otro convento femenino, el de Santa Isabel, monasterio de monjas comendadoras del hábito de San Juan y fundado a finales del siglo XV, en la collación de san Marcos, también se vio afectado aunque únicamente por la actuación una de sus monjas profesas, Francisca de Chaves.

Las informaciones acerca de esta mujer, de protagonismo destacado en los círculos protestantes de Sevilla aparecen desde el primer encarcelamiento del doctor Egidio. Al canónigo magistral ya le habían abierto un primer proceso en 1541, junto con Francisco de Vargas, por defender en público a Rodrigo de Valer. Lo había hecho después de la condena de este predicador lego originario de Lebrija, aunque el canónigo no parece haber sufrido entonces condena, pero sí fue abierta una causa contra él en aquel momento. Pero Francisca de Chaves entraría en la órbita del tribunal en torno a la reapertura de la causa contra el doctor Egidio que conduciría a su encarcelamiento, unos años más tarde. En 1549, a raíz de la propuesta de presentar el nombre del canónigo magistral para la mitra de Tortosa, la Inquisición reabrió aquel proceso, incorporando nuevos elementos y ampliando sus investigaciones. A consecuencia, varias personas del entorno del doctor Egidio huyeron: su «amigo», como lo califica un documento inquisitorial, Diego de la Cruz, su discípulo Luis Hernández, alias Luis del Castillo, y Juan Pérez de Pineda, clérigos que ocuparían posteriormente, los tres, destacadas funciones en las iglesias protestantes de Francia, Alemania, Flandes y Ginebra (AHN Inq. lib. 574, f. 216 r). Por lo menos dos de los familiares de Egidio, Luis Hernández y Pérez de Pineda, eran cercanos a la religiosa Chaves como ciertas deposiciones incluidas en otros procesos lo revelan (Ibid. leg. 4514 exp. 15). La «beata» como era calificada a finales de 1540 se halló comprometida por ciertos escritos de Luis Hernández que este le había dejado para ocultarlos y otros enviados, en particular un Diálogo consolatorio entre la iglesia chiquita que está en Sevilla y Jesucristo junto con otros cuadernos suyos(Ibid. lib. 574, f. 216 v). Aunque este diálogo se perdió, el cotejo de unas instrucciones mandadas a Francia para que Luis Hernández fuera interrogado con la sentencia de Chaves da una idea bastante precisa de su contenido: la instrucción pedía, en efecto, que

\footnotetext{
ha de ser preguntado si compuso el dicho diálogo y cuadernos que dejó encomendados a Francisca de Chaves, beata, y si escribió a la susodicha dende París las dichas cartas. Y ansí mismo sea preguntado que declare quién son las personas de aquella «iglesia chiquita» que dice en el Diálogo; y quién es el pastor; y quién son aquellos miembros del Antecristo que han quebrado los miembros sanos por podridos herejes; y quién son los tres fulano y fulano y fulano que no nombra y han cortado; y quién son aquellos que tienen lo que allí dice de bulas y jubileos; y qué doctrina de Evangelio es la que se persigue acá como en París, como por sus cartas escribe; y quién son los Herodes e Nerones que dice que los hay aquí; y qué doctrina la que acá y en París se persigue y en qué difiere de la doctrina común que tiene la Iglesia; y qué libros son los que allá dice que lee, que no se venden en público, y quién son los que los leen allá y acá; y qué es aquello que dice que allá hay muchas leciones pero de lo otro publicae nibil, quién lo predica o enseña, y en qué está la diferencia; y quién son los lobos hipócritas y fariseos de quien en el dicho Diálogo y en sus cartas habla (Ibid. lib. 574, fo 266 v).
}

SCRIPTA, Revista internacional de literatura i cultura medieval i moderna, núm. 8 / desembre 2016 / pp. 164-178 ISSN: 2340-4841 · doi:10.7203/SCRIPTA.8.9293 
Michel Boeglin. Religiosidad femenina y herejía: monjas y beatas «luteranas» ante la Inquisición de Sevilla en tiempos del Emperador

Claramente traslucía de las preguntas el carácter reformado del grupo sevillano de la Iglesia chiquita: las enseñanzas perseguidas en París como en Sevilla, evocadas en el escrito de Henández, no eran sino las doctrinas reformadas, que «difieren de la doctrina común» así como las leciones y libros que se profesaban o adquirían clandestinamente remitían a doctrinas censuradas. La Iglesia romana, calificada de iglesia de las «bulas y jubileos» era evocada a través, también, de los «miembros del Antecristo» según una terminología propia de los panfletarios protestantes y que parecía remitir a las autoridades del arzobispado sevillano dirigido por Fernando de Valdés desde 1546, el cual accedía al año siguiente a la dirección de la Suprema Inquisición y que empezaría el acecho a los evangélicos de Sevilla. Los «hipócritas» y «fariseos» remitían a los monjes y religiosos como destaca otro documento relativo al doctor Constantino (Pinilla 1995: 80) y aquellos cristianos convencidos de la importancia de las obras para su salvación. La sinécdoque Herodes y Nerones parecía una referencia a la represión inquisitorial que sufrían aquellos que afirmaban profesar doctrina de Evangelio, cuyo grupo era perseguido tanto en Sevilla como en París, donde habían hallado refugio los tres discípulos de Sevilla. Los tres «fulanos» que habían cortado (se infiere cortado con la Iglesia romana) parecían en efecto ser aquellos tres discípulos huidos, De la Cruz, Hernández y Pérez de Pineda, siendo este testificado poco después de su llegada a Paris en casa del aragonés Morillo, de comulgar al modo reformado, por ejemplo.

En su proceso, unos años más tarde, había declarado Chaves que para ella los papas y los que regían la Iglesia romana eran príncipes del mundo y que la doctrina que ella seguía era la luterana y «y cree y todo lo que ha leído en los papeles que ha tenido en su poder, señaladamente el que se intitula Diálogo consolatorio entre la iglesia chiquita que está en Sevilla, perseguida de los fariseos grandemente y entre el propio Jesucristo, de la cual iglesia chiquita ella había tenido por pastor al dicho doctor Egidio. Y que quisiera mucho tener un hombre en esta doctrina, porque las mujeres eran todas livianas» (AHN Inq. leg. 2075 exp. 46).

Esta iglesia chiquita contaba varios miembros en Sevilla y estaba directamente puesta bajo la autoridad del doctor Egidio a partir de finales de la década de 1540. A la muerte de Francisco de Vargas en 1546 y después de que saliera De la Fuente para la corte en 1548, el aragonés se había hallado solo a la cabeza del grupo disidente de Sevilla. Parece haberlo orientado, más particularmente después de las sesiones de 1547 del concilio de Trento acerca de la justificación, en un sentido más radical y con una organización clandestina en el momento en que las doctrinas que defendían acerca de la salvación, la caridad y la fe eran censuradas en el concilio. ${ }^{9}$ Como lo recalcaba su sentencia, consideraba que había dos iglesias, la romana y la otra, «chiquita, la cual estaba en esta ciudad de Sevilla, de verdaderos cristianos, la cual tenía su pastor y que las ovejas de ella eran los verdaderos cristianos de aquella cabaña, los cuales eran justos y que la otra, general y grande, regida y gobernada por malos cristianos y que estaba tiranizada y en poder de fariseos (AHN Inq. leg. 2075 exp. 46)».

9 Sobre la posible organización de esta iglesia bajo la autoridad de Egidio, ver Civale (2007: 210-216).

SCRIPTA, Revista internacional de literatura i cultura medieval i moderna, núm. 8 / desembre 2016 / pp. 164-178 ISSN: 2340-4841 · doi:10.7203/SCRIPTA.8.9293 
Michel Boeglin. Religiosidad femenina y herejía: monjas y beatas «luteranas» ante la Inquisición de Sevilla en tiempos del Emperador

Como bien reparó López Muñoz aquella oposición entre la Iglesia de los verdaderos cristianos (la iglesia chiquita) y la Iglesia universal, o la Iglesia invisible y la Iglesia visible mostraba muchas similitudes con la eclesiología protestante pero también con la de Constantino de la Fuente (López Muñoz 2011: 1, 205-207). Para el doctor Constantino, que se inscribía en la tradición de san Agustín, la Iglesia universal estaba constituida por los hombres que habían puesto su confianza en Dios y que por su participación a una misma fe y a unos mismos sacramentos eran miembros «públicos» de la Iglesia. Pero esta Iglesia cuya cabeza era Cristo estaba constituida de dos cuerpos o partes : los que estaban en comunión con el espíritu de Dios, miembros vivos y santificados por espíritu de Dios y los otros, los cuerpos muertos, aquellos cuya fe y obras no estaban en adecuación con la voluntad divina. En el Beatus vir De la Fuente escribía por ejemplo:

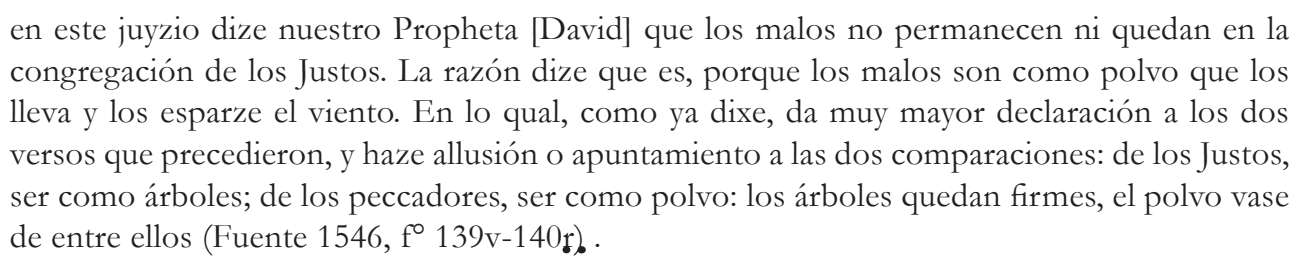
congregación de los Justos. La razón dize que es, porque los malos son como polvo que los lleva y los esparze el viento. En lo qual, como ya dixe, da muy mayor declaración a los dos versos que precedieron, y haze allusión o apuntamiento a las dos comparaciones: de los Justos, ser como árboles; de los peccadores, ser como polvo: los árboles quedan firmes, el polvo vase de entre ellos (Fuente 1546, fo 139v-140r).

Usaba De la Fuente de una asimilación de los justos, es decir los elegidos, a auténticos cristianos, justificados por la gracia de Dios, santificados, sino que les daba el significado que tiene dicha palabra en el Antiguo Testamento, el de persona fiel al culto verdadero de Dios. De Constantino de la Fuente, Chaves decía simplemente que su doctrina, como la de Egidio, la había puesto en el camino y encarecía el alto nivel de esta: «los mismos maestros de quien ella había sido enseñada en la dicha doctrina, que eran los doctores Egidio y Constantino, de los cuales estaba muy satisfecha, y del doctor Constantino más que de cuantos habían nascido en el mundo (AHN Inq. leg. 2075 exp. 46)», aunque sin nombrarlo como pastor de la iglesia de Sevilla ni como cabecilla del grupo, cuando el Reginaldo sugiere lo contrario.

La monja Francisca de Chaves salió condenada en el segundo auto de fe contra luteranos, en el del 22 de diciembre de 1560. En su proceso reconocía seguir la doctrina de los reformados alemanes, rechazando cualquier potestad del papa, reconociendo la justificación por la fe «porque el pecado que debíamos de Cristo por su pasión tenia pagados» y en la eucaristía reconocía seguir el «uso y sentido que los de Alemania tienen acerca de esto» en particular Martin Lutero «y otros que se le aventajan agora, de mejor entendimiento como Felipe Melancton y otros (ibid.)». Mujer leída, tenía Chaves según los inquisidores muchos libros «reprobados en que se contenían muchas blasfemias y herejias». Destacaba además por su marcado proselitismo, alentando otras mujeres a seguir las doctrinas reformadas y procurando, el caso merece notarse, imponer cierta disciplina religiosa entre las o los integrantes del cenáculo: «Y queriendo saber más de lo que convenía a su estado, se había juntado muchas veces con otras personas a hablar y platicar en las cosas de la fe, enseñándolas en la doctrina y errores que ella tenía, dándoles a entender que no era la que comúnmente se predicaba en la iglesia, mostrando tener compasión de las personas que no seguían su doctrina diciendo «Amargos de vosotros, no miráis que os vais al infierno'», porque seguían la católica doctrina cristiana y no la suya 
Michel Boeglin. Religiosidad femenina y herejía: monjas y beatas «luteranas» ante la Inquisición de Sevilla en tiempos del Emperador

(Ibid. leg. 2075 exp. 46)». Su amiga Ana de Illescas, «de que era participante con la dicha Francisca de Chaves en sus sermones» y «oía a la dicha Francisca de Chaves los sermones de Constantino que ella tenía escritos en papeles suyos», fue reconciliada. Esta tenía como libros únicamente uno escrito de la mano de Francisca de Chaves (una copia o una obra de doctrina religiosa hecha por la monja), el diálogo de la Suma de doctrina cristiana de Constantino y la Declaración sobre el paternóster de Erasmo (Ibid. leg. 4519, doc. 10).

Aunque los datos sobre Francisca de Chaves son escasos, un documento administrativo indicaba que estaba emparentada con Ana de Illescas y sus tres hermanos, igualmente acusados. Es más como lo señalaba un documento administrativo, «todos [ellos] son cercanos parientes de Isabel Martínez de Alvo, penitenciada (Ibid.; véase también Gil 2001: IV, 246; III, 560-561)» : Isabel Martínez de Alvo, la viuda de un importante mercader y famosa por haber sido la persona que custodiaba la biblioteca secreta de Constantino de la Fuente, en casa de quien el canónigo había escondido sus libros protestantes más comprometidos.

\section{Conclusión}

Llama así la atención en el grupo sevillano, a semejanza de lo que se observa en el de Valladolid, este mundo de sociabilidades femeninas a través del cual se difunden las doctrinas de los novadores y en que destacan mujeres tanto por su portentosa erudición teológica como su compromiso con la Reforma. A diferencia de lo que pudo afirmarse (Natalie Z. Davis 1979), en el siglo XVI la Reforma no modificó sustancialmente el papel tradicional de las mujeres en la sociedad en los países protestantes, reducido al ámbito del hogar y de la educación de niños muchas veces. Pero sí que en su inicio fue el vector de profundas esperanzas y tuvo una incidencia en el protagonismo de las mujeres (para el caso francés, ver Garrisson 1988: 96-97 y Mentzer 2001). En el desarrollo de las nacientes iglesias, el cuestionamiento de las viejas estructuras de la Iglesia romana y el anhelo de una reforma religiosa y de nuevas formas de piedad podía invitar a las mujeres a abrir una brecha en la dominación masculina en el mundo socio-religioso; y en aquellos círculos semi-clandestinos o clandestinos que llegarían a ser los conventículos luteranos, las mujeres lograron obtener un reconocimiento importante y ejercer un destacado protagonismo. El compromiso religioso, la lectura de los Evangelios, la influencia igualmente de determinados personajes, como la del doctor Egidio en diversos círculos de la élite sevillana, iba a modificar el papel de muchas mujeres en aquellos años.

Como lo había notado Nancy Roelker (1972: 227-228), las doctrinas reformadas y el calvinismo más particularmente ofrecían un modelo de autonomía y de acción política más allá del ámbito familiar. En Sevilla igualmente, bajo la influencia del doctor Egidio y sus discípulos, mujeres de la nobleza o de la alta sociedad, sensibles a las nuevas doctrinas mostrarán una fuerte receptividad a estas nuevas formas de piedad religiosa. Así, del caso de la marquesa de Villanueva, doña María Enríquez, hermana del Grande de España Per Afán de Ribera, cuya causa fue suspendida por orden de la Suprema, a pesar de contener varios elementos llamativos, para los que se conocen : el 
Michel Boeglin. Religiosidad femenina y herejía: monjas y beatas «luteranas» ante la Inquisición de Sevilla en tiempos del Emperador

tener por médico a Cristóbal Losada traductor al castellano de un catecismo calvinista e introductor con Juan Ponce de León de los libros de propaganda protestante llevados por Julián Hernández; el haber recibido estos libros junto con una carta de Juan Pérez de Pineda desde Ginebra y pagado diez ducados al portador de ellas. Pero también haber visitado las cárceles del Santo Oficio sobornando al ayudante del alguacil para entrevistarse con doña Ana de Deza, otra mujer de la nobleza, comprometida ella también ya en el proceso de Egidio de 1549, en particular por haber roto el aislamiento del canónigo durante su detención (AHN Inq. lib. 575, f 53v-54r carta del 22.10.1557). No obstante, a pesar de la gravedad de la situación y de la voluntad de los inquisidores de dar un castigo ejemplar y censurar de forma unívoca esta incursión en la herejía, en particular en miembros del estamento noble y eclesiástico, la corte inquisitorial, en casos como el de la marquesa de Villanueva, decidía suspender las actuaciones. De todas formas la violencia de la represión había bastado ya para señalar y materializar las nuevas fronteras confesionales. 
Michel Boeglin. Religiosidad femenina y herejía: monjas y beatas «luteranas» ante la Inquisición de Sevilla en tiempos del Emperador

\section{Bibliografía}

Bataillon Marcel (1991), Érasme et l'Espagne, ed. Ch. Amiel, Ginebra, Droz [1937 1a ed. francesa], 3 vol.

Boeglin, Michel (2006) «Contribution à l'étude des protestants de Séville (1557-1565). Sociabilités et sensibilité religieuses », Bulletin Hispanique, 108, Bordeaux, pp. 343-376.

- (2016), Réforme et dissidence religieuse en Castille au temps de l'Empereur. L'affaire Constantino de la Fuente (1505?-1559), Honoré Champion, París.

Civale, Gianclaudio (2007) «Domingo de Baltanás, monje solicitante en la encrucijada religiosa andaluza : confesión, Inquisición y Compañía de Jesús en la Sevilla del Siglo de Oro», Hispania sacra, 119, pp. 197-241

Davis, Natalie Z. (1979), Les cultures du peuple. Rituels, savoirs et résistances an XVTe siècle, Paris, AubierMontaigne, pp. 113-158.

Fuente, Constantino de la (1546), Exposicion del primerpsalmo de Danid, cuyo pricipio es Beatus vir, dinidida en seys Sermones : por el Doctor Constantino, s. l, s.n.

García Pinilla, Ignacio Javier (1995) «El doctor Constantino Ponce de la Fuente visto a través del parecer de la Vaticana (ms. Ottob. Lat. 782)», Archivo Hispalense, 238, pp. 65-102.

. (1999) «Más sobre Constantino Ponce de la Fuente y el parecer de la Vaticana», Cuadernos de investigación científica, 17, pp. 191-225.

Garrisson, Janine (1988) Les protestants au XVTe siècle, París, Fayard.

Gil, Juan (2000-2003) Los conversos y la Inquisición sevillana, Sevilla, Universidad, 8 vol.

Giles, Mary E. (coord.) (2000), Mujeres en la Inquisición : la persecución del Santo Oficio y el Nuevo Mundo, Ediciones Martínez Roca.

Huerga, Álvaro (1988) Historia de los alumbrados, 4 vol., vol. 4, Madrid, CSIC .

López Muñoz, Tomás (2011) La Reforma en la Sevilla del s. XVI, Sevilla, Eduforma, 2 vol.

Reginaldo 1991: El «Reginaldo Montano» : primer libro polémico contra la Inquisición española, Castrillo Benito, N. ed., Madrid, CSIC.

Mentzer,Raymond A. (2001) «La place et le rôle des femmes dans les Églises réformées », Archives de sciences sociales des religions, 113, 119-132.

Moreno Martínez, Doris (2013) «El protestantismo castellano revisitado: geografía y recepción», in Actas del congreso Hérésie et dissidences religieuses. La réception de la Réforme dans la péninsule Ibérique, Barcelona 28-30 de noviembre de 2013, M. Boeglin, D. Kahn, I. Fernández Terricabras (coord.), en prensa.

Morgado, Alonso (1587) Historia de Sevilla: En la qual se contienen sus antiguedades, grandezas y cosas memorables..., Sevilla, Imprenta de Andrea Pescioni y Juan de León. 
Michel Boeglin. Religiosidad femenina y herejía: monjas y beatas «luteranas» ante la Inquisición de Sevilla en tiempos del Emperador

Pastore, Stefania (2010) Una herejía española : Conversos, alumbrados e Inquisición (1449-1559) (trad. Del ital.), Madrid, Marcial Pons.

Roelker, Nancy (1972) «The appeal of calvinism to French noblewomen in the sixteenth century», Journal of interdisciplinary bistory, pp. 391-418.

Roper, Lyndal (1989) The Holy Household: Women and Morals in Reformation Augsburg, Oxford, Oxford University Press.

Sarrión Mora, Adelina (2003), Beatas y endemoniadas: mujeres heterodoxas ante la Inquisición, siglos XVI a XIX, Alianza Editorial, Madrid.

Spach, Robert C. (1995) «Juan Gil and Sixteenth-Century Spanish Protestantism», Sixteenth Century Journal, 26 (4), pp. 857-880.

Tellechea Idígoras, José Ignacio (2004), Doña Marina de Guevara, monja cisterciense ¿luterana?, Fundación Universitaria Española, Madrid.

Weber, Alison (2016) «The Historiographic Challenge», in Weber, Alison, ed. Devout Laywomen in the Early Modern World, Nueva York, Routledge. 